\title{
Complete Testicular Feminization Caused by an Amino-Terminal Truncation of the Androgen Receptor with Downstream Initiation
}

\author{
Sonia Zoppi, * Carol M. Wilson, ** Madeleine D. Harbison, ${ }^{5}$ James E. Griffin, * Jean D. Wilson, * Michael J. McPhaul, * \\ and Marco Marcelli * \\ Departments of ${ }^{*}$ Internal Medicine and ${ }^{\ddagger}$ Pharmacology, The University of Texas Southwestern Medical Center at Dallas, Dallas, \\ Texas 75235-8857; and ${ }^{\S}$ Department of Pediatrics, The New York Hospital-Cornell Medical Center, New York 10021
}

\begin{abstract}
We have characterized the molecular defect causing androgen resistance in two 46,XY siblings with complete testicular feminization. Although binding studies in genital skin fibroblasts showed a reduced $B_{\max }$, an increased dissociation rate of ligand, and an $8 \mathrm{~S}$ peak of dihydrotestosterone binding on sucrose density gradient centrifugation, no immunoreactive androgen receptor (AR) was detected in immunoblots using anti-NH $\mathrm{NH}_{2}$-terminal antibodies, suggesting an abnormal amino terminus. Sequence analysis of the $A R$ gene revealed a point mutation $\mathbf{C A G}$ $\rightarrow$ TAG (Gln $\rightarrow$ Stop) at nucleotide 340 . In vitro mutagenesis studies suggest the synthesis of the mutant $A R$ is initiated downstream of the termination codon at reduced levels and that each molecule is functionally impaired. These results define a novel mechanism causing androgen resistance: the combination of decreased amount and functional impairment of AR caused by an abnormality within the amino terminus of the receptor. These findings suggest that domains important to the in vivo function of the receptor reside within the amino terminus and that disruption of these domains can occur with only subtle effects on receptor binding. Identification of this mutation made it possible to identify the mutant allele within the family and to ascertain antenatally that it was not present in a 46,XY fetal sibling of the proband at 9 wk gestation. (J. Clin. Invest. 1993. 91:1105-1112.) Key words: steroid • receptor • genetic • mutation • resistance
\end{abstract}

\section{Introduction}

Mutations in the human androgen receptor $(\mathrm{AR})^{1}$ cause a variety of syndromes of androgen resistance, ranging from women with complete testicular feminization to undervirilized infertile men (1). These disorders have been classified on the basis of the level and character of androgen binding in cultured genital skin fibroblasts into groups of patients in which no specific binding is detected (receptor binding negative), those with reduced quantities of qualitatively normal receptor binding (receptor binding reduced), those with normal levels of qualita-

Address correspondence to Michael J. McPhaul, M.D., Department of Internal Medicine, University of Texas Southwestern Medical Center, 5323 Harry Hines Boulevard, Dallas, TX 75235-8857. 1992.

Received for publication 1 June 1992 and in revised form 5 October

1. Abbreviations used in this paper: AR, androgen receptor; CAT, chloramphenicol acetyl transferase; CHO, Chinese hamster ovary; CMV, cytomegalovirus; MMTV, mouse mammary tumor virus.

J. Clin. Invest.

(c) The American Society for Clinical Investigation, Inc.

0021-9738/93/03/1105/08 \$2.00

Volume 91, March 1993, 1105-1112 tively abnormal receptor protein, and a final group with normal levels of qualitatively normal receptor binding (receptor binding positive). The cloning of the cDNA for the AR has permitted the elucidation of the molecular defect in a number of families. Receptor binding negative androgen resistance has been traced to gene deletions $(2,3)$, premature termination of the receptor protein (4-7), and amino acid substitutions within the hormone-binding domain $(8,9)$. Qualitative abnormalities can be caused by single amino acid replacements in the hormone-binding domain $(10,11)$, and receptor binding positive androgen resistance is frequently due to amino acid substitutions in the DNA-binding domain $(12,13)$.

In the current work we report the analysis of the AR gene in two siblings with complete testicular feminization and a diminished amount of qualitatively abnormal AR. The elucidation of this mutation permitted the antenatal analysis of the AR gene in a fetus at risk.

\section{Methods}

Clinical summary. Subject R776 was identified at birth as a female with bilateral inguinal testes. Subsequent evaluation revealed the presence of testes in the hernia, a 46,XY karyotype, and the phenotype of testicular feminization. Her younger sister (R782) had a normal female phenotype at birth but was found on further evaluation to have a 46, XY karyotype (Fig. $1 A$ ). The dihydrotestosterone binding capacities $\left(\mathrm{B}_{\max }\right)$ in fibroblast monolayers cultured from biopsies of labia majora were 7 and $10 \mathrm{fmol} / \mathrm{mg}$ protein for subjects R776 and R782, respectively (Table I).

After the mutation responsible for androgen resistance in this family was defined, the mother of the propositus became pregnant. As she wished to ascertain whether she was carrying an affected fetus, amniocentesis and chorionic villus sampling were performed at week 8 , and a portion of this sample was used to grow primary cultures of amniotic fluid cells. Fetal DNA was prepared directly from the chorionic villus sample and from confluent culture of villus cells. Sequence analysis of the fetal AR gene was carried out as described below.

$D N A$ preparations and AR gene analysis. Confluent monolayers of fibroblasts were scraped into ice-cold PBS, pelleted, and processed as described (4). All eight coding exons of the human AR gene are present and grossly intact in patients R776 and R782 (data not shown). Amplification and sequence analysis of the human AR was performed by polymerase chain reaction amplification and dideoxy sequencing of the coding exons as before (5). The sequence of the GGC repeats in exon 1 was not determined.

Immunoblots. Immunoblots were performed as described by Wilson et al. (14). In brief, genital skin fibroblasts from subjects R776 and R782 and from a normal control (704) were homogenized in SDSPAGE loading buffer and centrifuged for $30 \mathrm{~min}$ at $200,000 \mathrm{~g}$. Aliquots of the supernatant fraction, termed cell extract, were applied to a $7.5 \%$ acrylamide gel containing $3.5 \mathrm{nM}$ sodium dodecyl sulfate, separated by electrophoresis, transferred to nitrocellulose, and incubated sequentially with affinity-purified polyclonal antibodies and with ${ }^{125}$ I-labeled anti-rabbit IgG. Immunoreactive bands were visualized by autoradiography. COS cells, transiently transfected with cytomegalovirus (CMV) cDNA expression vectors encoding the normal (CMV3.1) or mutant 
A

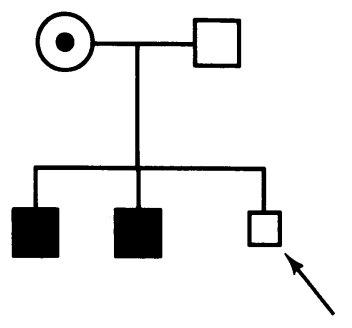

B

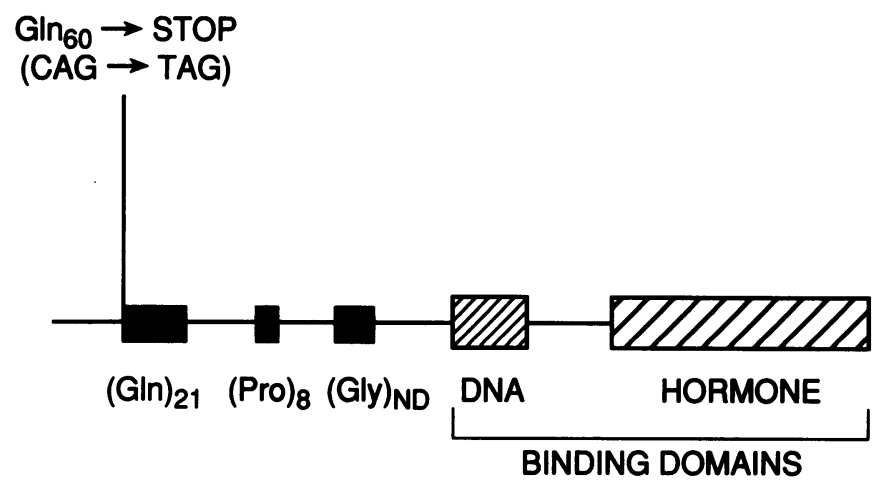

Heterozygous Mother

Father

Complete Testicular Feminization

Normal 2 month old $46, X Y$ fetus
(CMV776) AR and with the control plasmid CMV- $\beta$-galactosidase, were analyzed for AR immunoreactivity in the same way. Antibodies were obtained by immunizing rabbits $\mathrm{U} 402$ and R489 with peptides containing the human AR amino acid sequences 1-21 or 898-917, respectively, to elicit anti- $\mathrm{NH}_{2}$-terminal antibodies or anti-COOH-terminal antibodies as described (15). Anti-internal A antibodies were obtained from rabbit $\mathrm{U} 407$ immunized by the same protocol with a peptide, termed internal $A$, containing the following amino acid sequence: $\mathrm{NH}_{2}$-S-E-G-S-S-S-G-R-A-R-E-A-S-G-A-P-T-S-S-K-D-C$\mathrm{COOH}$. The internal A peptide corresponds to the 200-220 amino acid sequence of human AR, with the addition of a $\mathrm{COOH}$-terminal Cys residue. The positions of each of these epitopes within the AR is depicted schematically in Fig. 2.

Site-directed mutagenesis. The mutation detected in subjects $\mathbf{R} 776$ and R782 is located at nucleotide 340 . This nucleotide is located between two restriction sites, Afl II and NarI, that are unique to the AR cDNA and to the expression vector CMV3.1. The segment of the hu- man AR of subjects R776 and R782 containing the nucleotide substitution at position 340 was amplified by the polymerase chain reaction, digested with the restriction enzymes Afl II and NarI, and inserted into the AR expression plasmid CMV3.1 digested with the appropriate restriction endonucleases. After transformation into Escherichia coli cells, individual colonies were grown, and the plasmid DNA was isolated. The presence of the desired nucleotide substitution at position 340 within the resulting plasmid was confirmed by nucleotide sequence analysis.

Cell culture and transfection. Chinese hamster ovary (CHO), CV1, and COS cell lines from the American Type Culture Collection (Rockville, $M D)$ were maintained as described $(5,9,13)$. Transfections were performed by using the calcium phosphate precipitation method (16) as before (5).

Ligand binding and sucrose density gradient analysis of AR in genital skin fibroblasts and transfected cells. $\mathrm{CHO}$ and $\mathrm{CV} 1$ cells were used in stable transfection experiments to examine the effect of the mutation

Table I. Ligand-Binding Properties of the Normal and Mutant ARs in Genital Skin Fibroblast Cultures and Transfected CHO Cells

\begin{tabular}{|c|c|c|c|c|c|c|c|c|c|}
\hline & \multirow[b]{2}{*}{$\mathbf{B}_{\max }$} & \multirow[b]{2}{*}{ Apparent $K_{\mathrm{d}}$} & \multirow[b]{2}{*}{ Thermolability } & \multicolumn{6}{|c|}{$\begin{array}{l}\text { Dissociation rate: } \\
\text { Hours }\end{array}$} \\
\hline & & & & 0 & 1 & 2 & 3 & 4 & 5 \\
\hline & $\mathrm{fmol} / \mathrm{mg}$ protein & $n M$ & & \multicolumn{6}{|c|}{$\%$ of specific binding remaining } \\
\hline \multicolumn{10}{|c|}{ A. Genital skin fibroblasts } \\
\hline R776 & 7 & 0.08 & Normal & 100 & 67 & 60 & 47 & 38 & 27 \\
\hline $\mathrm{R} 782$ & 10 & 0.2 & Normal & $\mathrm{ND}^{*}$ & & & & & \\
\hline Control (704) & 36 & 0.07 & Normal & 100 & 92 & 85 & 80 & 70 & 60 \\
\hline \multicolumn{10}{|c|}{ B. Transfected $\mathrm{CHO}$ cells } \\
\hline CHO-CMV776 & 83 & 0.2 & Normal & 100 & 72 & 60 & 48 & ND & 30 \\
\hline CHO-CMV3.1 & 222 & 0.4 & Normal & 100 & 95 & 80 & 70 & ND & 58 \\
\hline
\end{tabular}

$A$. Binding characteristics detected in cultured genital skin fibroblasts of a normal control (704) and subjects R776 and R782. B. Binding characteristics detected in CHO cells stably transfected with the normal AR cDNA (CMV3.1) or with the AR expression plasmid containing the mutation detected in subjects R776 and R782 (CMV776).

* ND, not done. 
Figure 2. (A) Schematic representation of the human AR protein and position of three internal methionines at amino

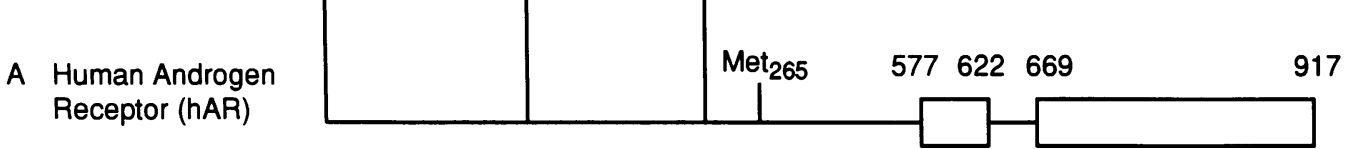
acid residues 188,244 , and 265. (B) Synthetic peptides used to raise antibodies that recognize $\mathrm{NH}_{2}$-terminal, internal A, or $\mathrm{COOH}$-terminal re-

B Synthetic Peptide Antigens

$\mathrm{N}$-Terminal

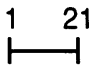
21

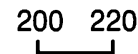

C-Terminal

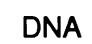

L Binding Domains gions of the human AR. (C) Predicted apparent molecular mass of AR 898917 proteins initiated from internal methionine residues 188,244 , or 265 .

$110 k D$

These estimates are derived from the observed value of $\sim 110 \mathrm{kD}$ obtained for the full-length AR protein (917 amino acids, molecular weight $=98,918$ ). on the ligand binding properties of the receptor. In these experiments cDNAs encoding the normal AR or the mutation detected in subjects R776 and R782 were cotransfected with the selectable marker pSV2neo (17) by using the calcium phosphate precipitation method. After selection with medium containing $400 \mu \mathrm{g} / \mathrm{ml}$ of the antibiotic G418, pools of cells ( 50-200 individual colonies) were propagated for use in monolayer binding experiments to determine the ligand-binding characteristics of the AR protein. Monolayer cultures were incubated with different concentrations of $\left[{ }^{3} \mathrm{H}\right]$ dihydrotestosterone in the presence or absence of a 500-fold excess of unlabeled ligand. After incubation for $1 \mathrm{~h}$ at $37^{\circ} \mathrm{C}$, the culture was rinsed, harvested, and assayed for protein and tritiated steroid content as before (18).

Thermolability was assessed by incubating monolayer cultures with increasing concentrations (fibroblasts) or with a saturating concentration ( $2 \mathrm{nM}$ ) (transfected cells) of [ $\left.{ }^{3} \mathrm{H}\right] 5 \alpha$-dihydrotestosterone at 37 and $41^{\circ} \mathrm{C}$ for $1 \mathrm{~h}$. After incubation the cells were harvested and processed as above (19). The rate of ligand dissociation was examined by preincubating parallel cultures with $2 \mathrm{nM}\left[{ }^{3} \mathrm{H}\right]$ mibolerone for $1 \mathrm{~h}$ at $37^{\circ} \mathrm{C}$ in the presence or absence of excess unlabeled mibolerone. At time 0 the medium containing radioactive ligand was removed and replaced with medium containing $2 \mathrm{nM}$ cold mibolerone, and the incubation was continued for $5 \mathrm{~h}$. The amount of specific radioactive mibolerone remaining at hourly intervals was compared with the level of binding in samples to which no competitor steroid had been added (19). Sucrose density gradient centrifugation analysis of labeled cytosol from fibroblasts was performed in TEGM- 10 buffer $(50 \mathrm{mM}$ Tris$\mathrm{HCl}, 1 \mathrm{mM}$ EDTA, 10\% [ $\mathrm{vol} / \mathrm{vol}$ ] glycerol, $1 \mathrm{mM}$ 2-mercaptoethanol, and $10 \mathrm{mM}$ sodium molybdate, $\mathrm{pH} 7.4$ ) as described previously (19).

Analysis of transactivation activity. CV1 cells were used in transient transfection experiments to examine the effect of the mutation on the transactivation activity of the receptor (5). Transfections were performed by the calcium phosphate precipitation method with plasmids encoding normal or mutant AR, the reporter plasmid MMTV-CAT, and a control plasmid, CMV- $\beta$-galactosidase. After transfection the cells were incubated in medium containing $5 \%$ charcoal-stripped serum in the presence or absence of $2 \mathrm{nM}$ dihydrotestosterone. After 48 $h$ the cells were harvested and assayed for chloramphenicol acetyl transferase (CAT) (20) and $\beta$-galactosidase activity (21). In these experiments the level of CAT activity reflects the transactivation activity of the different ARs, and $\beta$-galactosidase activity is assessed to correct for the efficiency of transfection.
COS cells were transiently transfected by the calcium phosphate precipitation method with normal or mutant $A R$ plasmids and with the control plasmid CMV- $\beta$-galactosidase. Extracts from these cells were used in immunoblot analysis and to assay $\beta$-galactosidase activity.

\section{Results}

Fibroblasts from subjects $R 776$ and $R 782$ express a reduced amount of qualitatively abnormal $A R$ in binding assays. Genital skin fibroblasts established from subjects R776 and R782 consistently demonstrated a low but detectable level of specific androgen binding. Although this level varied somewhat from assay to assay, the amount averaged $\sim 8 \mathrm{fmol} / \mathrm{mg}$ protein (range 5-10). Ligand binding was stable at elevated temperature but exhibited an accelerated ligand dissociation rate ( Table I). Sucrose density gradient analysis of ligand-receptor complexes containing AR from strain R776 prepared in low ionic strength buffer revealed a sedimentation profile similar to that obtained with normal AR (data not shown).

Anti- $\mathrm{NH}_{2}$-terminal antibodies do not detect androgen receptor in immunoblots of fibroblast strain $R 776$ and $R 782$. The level of immunoreactive AR in fibroblasts was assessed with antibodies (U402) that recognize the amino terminus of the receptor protein (15). As shown in Fig. 3, samples R776 or R782 containing 370 or $284 \mu \mathrm{g}$ protein, respectively (binding capacity $>2$ fmol dihydrotestosterone), had no detectable immunoreactive AR whereas a 10- $\mu \mathrm{g}$ sample of protein from the normal genital skin fibroblast strain 704 (binding capacity $\sim 0.4$ fmol dihydrotestosterone) produced a visible $110-\mathrm{kD}$ AR band. These results suggested that subjects R776 and R782 produce AR protein in which the amino terminal region is absent or abnormal.

The AR genes of subjects $R 776$ and $R 782$ contain a premature termination codon in exon 1 . Analysis of the nucleotide sequence of the AR coding segment in DNA from subjects R776 and R782 detected a single nucleotide substitution at nucleotide 340 in exon 1 . This substitution results in the con- 


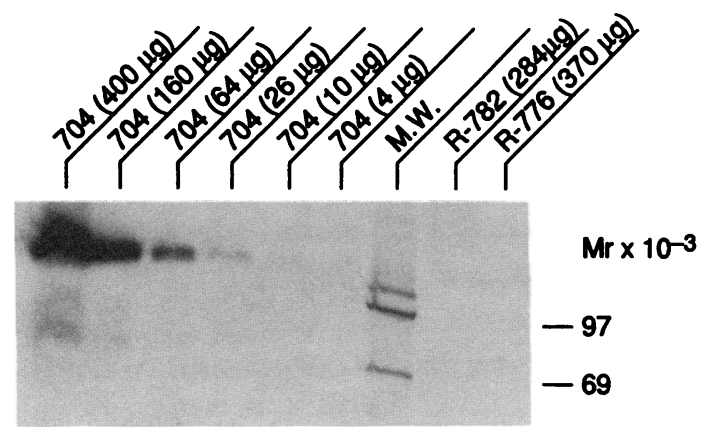

Figure 3. Absence of immunoreactive AR in immunoblots of cell extracts prepared from genital skin fibroblasts of subjects R776 and R782. The indicated quantities of cell extract were fractionated by electrophoresis on a 7.5\% SDS polyacrylamide gel, transferred to nitrocellulose, and probed with antibodies directed at the $\mathrm{NH}_{2}$ terminus of the AR. The control (strain 704) shows a major 110-kD immunoreactive band. No immunoreactive AR band is detected in fibroblasts established from subjects R776 or R782.

version of a codon (CAG) encoding glutamine 60 into a termination codon (TAG). The remainder of the AR gene carried by these two individuals is otherwise normal except for minor differences in the lengths of glutamine homopolymeric segment. The size of the glycine homopolymeric region was not determined. These changes are shown schematically in Fig. 1 $B$. Although we demonstrated that the same mutation is present in subject $\mathrm{R} 782$, the mutant gene is referred to as that predicted for subject $\mathrm{R} 776$ and the mutation is denoted as Q60X in the remainder of this manuscript.

Consequences of termination of the receptor protein at amino acid 60. The premature termination codon in exon 1 would be expected to cause the termination of the receptor protein at amino acid residue 60 . The presence of specific ligand binding despite the presence of the premature stop codon suggested that initiation of translation must occur at a point on the AR mRNA 3' to the premature termination codon.

To examine the effects of this mutation in detail, the $\mathrm{C} \rightarrow \mathrm{T}$ nucleotide substitution was inserted into an AR cDNA in the eukaryotic expression vector CMV3. This expression plasmid (CMV776) or an expression plasmid encoding the normal AR (CMV3.1) were transfected into CHO cells using the selectable marker pSV2neo and analyzed for the presence and quantity of specific androgen binding. As shown in Table I, the receptor binding in cells stably transfected with the CMV776 plasmid has similar characteristics to that of the AR in fibroblasts cultured from the patient, as evidenced by a normal apparent $K_{\mathrm{d}}$ and an increased dissociation rate. These findings support the possibility that a truncated AR protein is synthesized by initiation at a downstream initiator methionine and that this mutant receptor is capable of binding hormone with normal affinity.

The mutant AR predicted for subject $R 776$ can activate an androgen-responsive reporter gene. To assess the capacity of the truncated AR protein for gene activation, cDNAs encoding the normal and mutant ARs were cotransfected into recipient cells with a reporter plasmid, mouse mammary tumor virus (MMTV)-CAT. After incubation with ligand, the level of transactivation of the reporter gene was assayed by comparing the basal and stimulated levels of CAT activity achieved by the proteins encoded by the normal and mutant AR cDNAs (Fig. 4). These studies show that the mutant $A R$ is impaired in its capacity to activate a reporter gene. Furthermore, when $200 \mathrm{ng}$ of the CMV776 expression plasmid are transfected, the reporter gene is activated to only $\sim 8 \%$ of the level observed with transfection of $200 \mathrm{ng}$ of normal AR cDNA (CMV3.1). Interestingly, as the amount of the mutant expression plasmid transfected is increased, the level of gene activation also increases, suggesting that the CMV776 expression plasmid leads to the synthesis of a reduced quantity of AR protein (Fig. 5 and Table II). Nevertheless, transfection of an increased amount of cDNA encoding the mutant AR does not result in a normal amount of transcriptional activity of the MMTV-CAT reporter. The maximal amount of activity reached by mutant CMV776 (which occurs when $20 \mu \mathrm{g}$ of cDNA are transfected) is $\sim 30 \%$ compared with the maximal activity reached by the normal AR (Fig. 5 and Table II). As noted previously (5), increasing the amount of transfected normal AR (CMV3.1) results in a peak of activity at concentrations between $200 \mathrm{ng}$ and $1 \mu \mathrm{g}$, followed by a decline in activity when larger amounts of normal AR cDNA are transfected (Fig. 5 and Table II).

The Q60X mutation leads to a marked decrease in the level of AR expression in transiently transfected cells. The results of binding studies in fibroblasts and of the transient transfection experiments suggested this mutation impairs the level of AR expression in cells. To examine this we transfected COS cells with equivalent amounts of normal (CMV3.1) or mutant (CMV776) expression vector. $2 \mathrm{~d}$ after transfection, cells were harvested and assayed for immunoreactive AR using antibodies that recognize the $\mathrm{COOH}$ - or $\mathrm{NH}_{2}$-terminal segments of the AR or the internal A sequence that contains amino acids 200 220 of the human AR. As reported previously (15), a similar pattern of immunoreactive AR proteins with major bands at $\sim 110$ and $65 \mathrm{kD}$ is obtained when immunoblots of extracts from COS cells transfected with CMV3.1 are probed with antibodies to the $\mathrm{COOH}$ terminus (Fig. $6 \mathrm{~A}$ ) or with antibodies to the $\mathrm{NH}_{2}$ terminus (data not shown). Anti-internal A peptide antibodies also react with the $110 \mathrm{kD}$ full-length $\mathrm{AR}$ protein in these samples but produce a different pattern of smaller immunoreactive proteins (Fig. $6 \mathrm{~B}$ ). As expected, no 110-kD AR

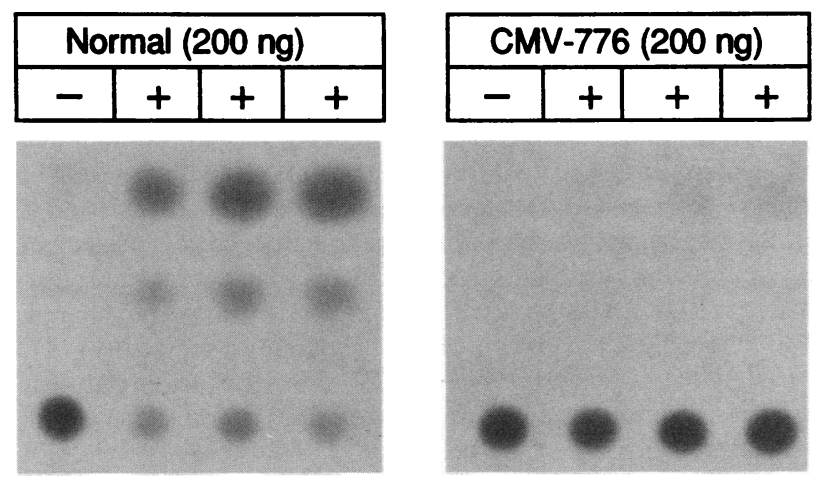

Figure 4. The mutant AR predicted for subjects R776 and R782 is severely impaired in cotransfection assays of receptor function. Cultures of $\mathrm{CV} 1$ cells were transfected with a mixture of the receptor plasmid MMTV-CAT ( $10 \mu \mathrm{g})$, a control plasmid (CMV- $\beta$-gal) (1 $\mu \mathrm{g}$ ), and $200 \mathrm{ng}$ of normal or mutant ARs. After incubation with no steroid or $2 \mathrm{nM} 5 \alpha$-dihydrotestosterone for $48 \mathrm{~h}$, cell extracts were prepared and assayed for CAT and $\beta$-galactosidase activity. Each lane represents an assay of a single transfected culture. - indicates no steroid and + indicates $2 \mathrm{nM} 5 \alpha$-dihydrotestosterone. 

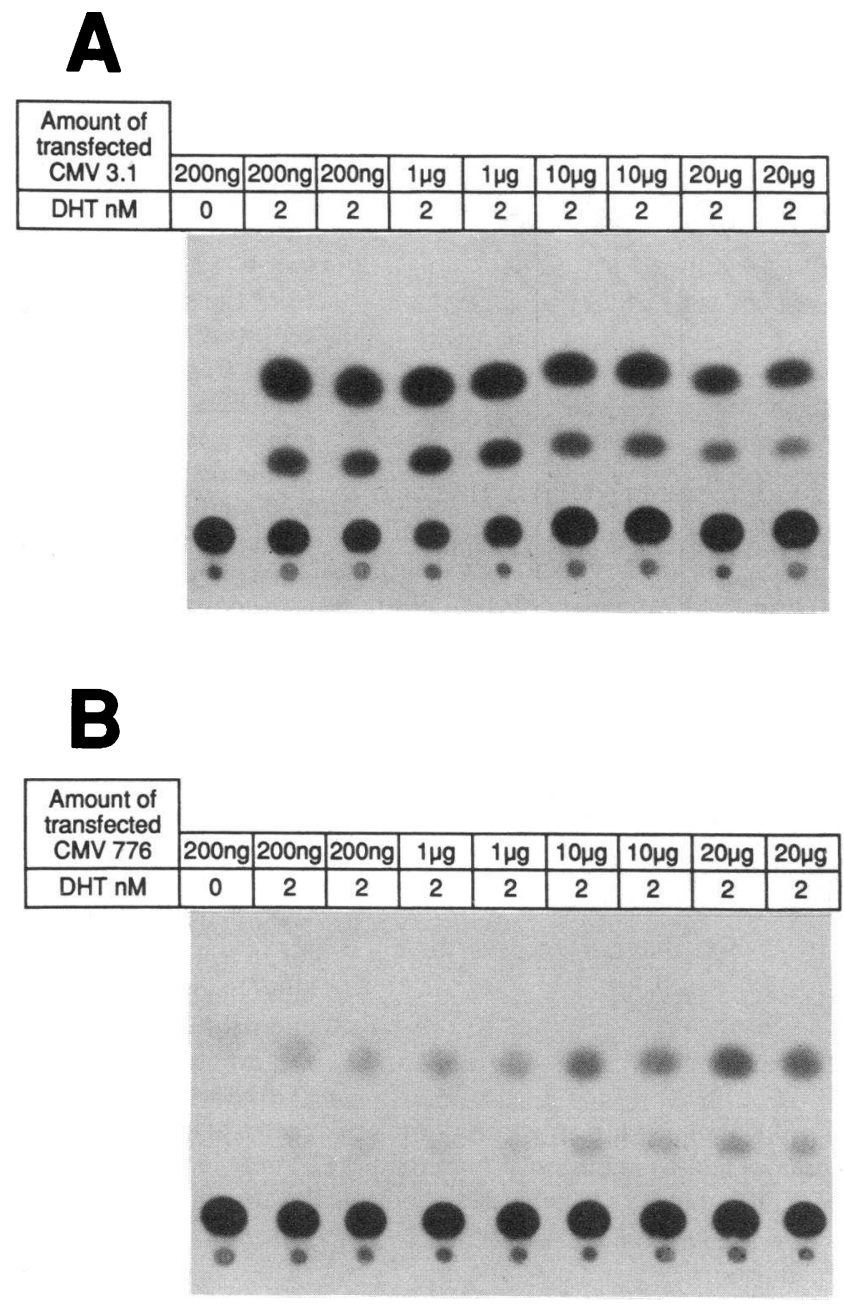

Figure 5. Increasing the amount of transfected AR causes an increase in the induction of the reporter gene activity in cells transfected with the mutant AR. Cell cultures were transfected with $10 \mu \mathrm{g}$ of the reporter plasmid (MMTV-CAT), $1 \mu \mathrm{g}$ of the control plasmid (CMV$\beta$-gal), and varying levels of normal $(A)$ or mutant $(B)$ AR expression plasmid. After incubation with no steroid or $2 \mathrm{nM} 5 \alpha$-dihydrotestosterone for $48 \mathrm{~h}$, cell cultures were harvested and assayed for CAT and $\beta$-galactosidase activities.

protein was detected in CMV776-transfected COS cells by antibodies to the $\mathrm{NH}_{2}$ terminus (data not shown), $\mathrm{COOH}$ terminus (Fig. $6 \mathrm{~A}$ ), or the internal A sequence (Fig. $6 \mathrm{~B}$ ). However, anti-COOH-terminus antibodies and antiinternal A antibodies both react with an $\sim 87-\mathrm{kD}$ protein that is present in these samples but not in untransfected COS cells or COS cells transfected with CMV3.1 (Fig. $6 A$ and $B$ ). Although these results do not exclude the synthesis of shorter AR fragments, the detection of an $\sim 87-\mathrm{kD}$ band using antibodies directed at the $\mathrm{COOH}$ terminus and internal A regions of the receptor and the paucity of smaller immunoreactive proteins argue strongly that initiation occurs principally at the methionine residue 188. These results are consistent with initiation of AR synthesis at methionine 188 to produce a truncated $A R$ that lacks the $\mathrm{NH}_{2}$ terminus but retains the $\mathrm{COOH}$ terminus and internal $\mathrm{A}$ sequence. The positions of potential initiation sites and expected sizes of AR species derived from such initiation sites are shown schematically in Fig. 2.
Fig. 6 shows an immunoblotting experiment in which 1, 2, and $4 \mu \mathrm{g}$ of protein from cells transfected with CMV3.1 were compared with $156 \mu \mathrm{g}$ of protein from cells transfected with the CMV776 expression plasmid. The efficiency of transfection in this experiment was monitored by cotransfecting the constitutively active reporter plasmid CMV- $\beta$-galactosidase and by assaying cell extracts for $\beta$-galactosidase activity. As $\beta$-galactosidase activity was similar in cell extracts transfected either with CMV3.1 or with CMV776 ( $\sim 0.4 \mathrm{U} / \mathrm{mg}$ protein $)$, the relative amount of AR expressed in these cell extracts could be compared on the basis of the intensity of the major immunoreactive bands corrected for the amount of protein loaded in each lane. Using this approach, we estimate that the amount of AR protein in COS cells transfected with the mutant receptor cDNA is $\sim 100$-fold lower compared with COS cells transfected with normal AR cDNA.

Prenatal diagnosis of an AR genotype. During the course of these studies, the proband's mother became pregnant and wished to ascertain whether she was carrying an affected fetus. For this reason, amniocentesis and chorionic villus sampling were performed at week 8 . After karyotype analysis revealed a 46, XY genotype, DNA was prepared from both biopsied chorionic villi and cultured amniotic fluid cells. Samples derived from four separate amplifications were subjected to nucleotide sequence analysis and found to reveal a normal AR gene sequence at amino acid position 60 . The expectation of normal male sexual development was confirmed by the detection of a phallus by ultrasonography at week 16 and by the presence of a normal male phenotype of the infant at birth.

\section{Discussion}

The present work was undertaken to define the molecular defect causing androgen resistance in two siblings with complete testicular feminization associated with reduced but demonstra-

Table II. Transcriptional Activity of the ARs Encoded by the Normal (CMV3.1) and Mutant (CMV776) Expression Plasmids

\begin{tabular}{cccc}
\hline & $\begin{array}{c}\text { Amount of } \\
\text { transfected cDNA }\end{array}$ & $\begin{array}{c}\text { CAT } \\
\text { conversion }\end{array}$ & $\begin{array}{c}\text { Normal AR } \\
\text { activity }\end{array}$ \\
\hline & & & $\%$ \\
CMV3.1 & $200 \mathrm{ng}$ & $42 \pm 6$ & 100 \\
& $1 \mu \mathrm{g}$ & $42 \pm 13$ & 100 \\
& $10 \mu \mathrm{g}$ & $19 \pm 11$ & 44 \\
$\mathrm{CMV-776}$ & $20 \mu \mathrm{g}$ & $10 \pm 1$ & 22 \\
& $200 \mathrm{ng}$ & $3 \pm 2$ & 8 \\
& $1 \mu \mathrm{g}$ & $6 \pm 3$ & 13 \\
& $10 \mu \mathrm{g}$ & $8 \pm 3$ & 18 \\
& $20 \mu \mathrm{g}$ & $13 \pm 6$ & 30 \\
\hline
\end{tabular}

The normal (CMV3.1) and mutant (CMV-776) AR expression plasmids were cotransfected into $\mathrm{CV} 1$ cells with the reporter plasmid MMTV-CAT $(10 \mu \mathrm{g})$ and the control plasmid CMV- $\beta$-galactosidase $(1 \mu \mathrm{g})$. After transfection, the cultures were stimulated with ligand for $48 \mathrm{~h}$ and assayed for CAT and $\beta$-galactosidase activities. The results are expressed as \% CAT conversion per assay. The results are similar when corrected for $\beta$-galactosidase activity (data not shown). Each value represents the average \pm SD from three representative experiments. Each point in each experiment was derived from duplicate transfections. 

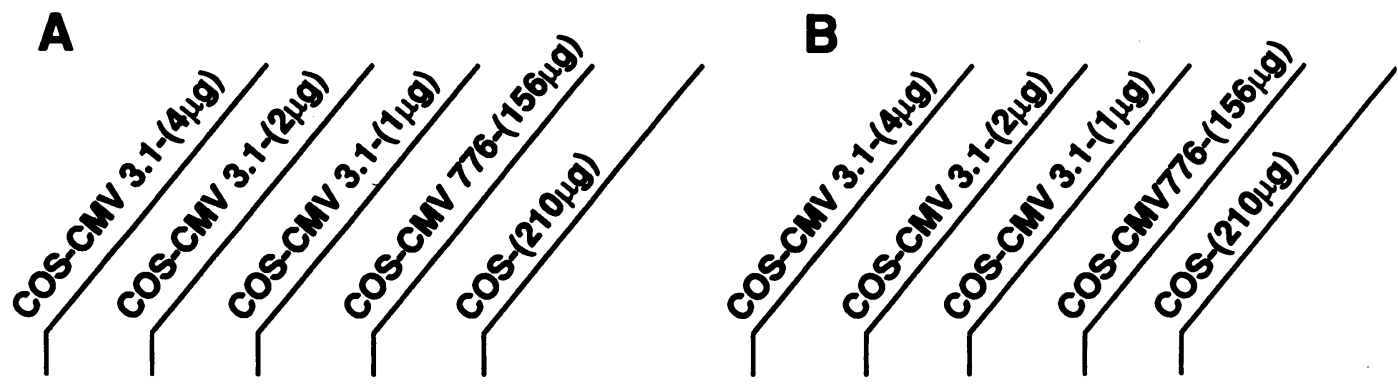

Figure 6. Reduced levels of a truncated AR protein are detected in COS cells transfected with the AR cDNA encoding the Q60X mutation carried by subjects $\mathrm{R} 776$ and R782. Extracts from transfected COS cells were fractionated by electrophoresis on 7.5\% SDS polyacrylamide gels, transferred to nitrocellulose, probed with antibodies that recognize the $\mathrm{COOH}$ terminus $(A)$ or the amino acid 200-220 sequence (internal $A)(B)$ of the AR. Immunoreactive bands were labeled with ${ }^{125}$ I anti-rabbit IgG and visualized by autoradiography. The immunoblot obtained with anti$\mathrm{COOH}$-terminal antibodies $(A)$ was exposed for $16 \mathrm{~h}$. The immunoblot obtained with antiinternal $\mathrm{A}$ antibodies was exposed for $1.5 \mathrm{~h}$. COS cells transfected with the normal AR cDNA (CMV3.1) express the full-length immunoreactive AR protein with an apparent molecular mass of $110 \mathrm{kD}$. An $\sim 87-\mathrm{kD}$ immunoreactive band is detected by anti-COOH-terminus antibodies $(A)$ and by antiinternal $\mathrm{A}$ antibodies $(B)$ only in the lane containing cell extracts deriving from COS cells transfected with plasmid CMV-776. The numbers in parentheses indicate the amount of protein that was loaded in each lane.

ble ligand binding. Immunoreactive $\mathrm{AR}$ was not detected using antibodies directed at the $\mathrm{NH}_{2}$ terminus of the $\mathrm{AR}$ protein to probe immunoblots of solubilized cultured genital skin fibroblasts from these individuals. Sequence analysis of the AR genes revealed a single nucleotide replacement at nucleotide 340 that changes the codon for glutamine (CAG) at position 60 in the normal $\mathrm{AR}$ into a premature termination codon ( $\mathrm{TAG}$ ).

The inability of the anti- $\mathrm{NH}_{2}$-terminal antibodies to detect immunoreactive $\mathrm{AR}$ in cultured genital skin fibroblasts from subjects R776 and R782, despite the presence of measurable $\left[{ }^{3} \mathrm{H}\right]$ dihydrotestosterone binding, led us to investigate the possibility that synthesis is initiated at an internal methionine to produce AR protein truncated at the $\mathrm{NH}_{2}$ terminus. Since an AR protein initiated at an internal methionine would not be recognized by antibodies raised against a synthetic peptide derived from the $\mathrm{NH}_{2}$-terminal amino acid sequence, we used antibodies raised against the $\mathrm{COOH}$-terminal amino acid sequence of the AR or against a peptide (internal A) corresponding to the amino acid 200-220 sequence to identify the truncated protein in cell expression experiments. Using this method, we demonstrated an immunoreactive AR, smaller than the normal protein, in COS cells transfected with a cDNA encoding the R776 mutant AR (CMV776). The presence of this $87-\mathrm{kD}$ protein is consistent with the hypothesis that subjects $R 776$ and $R 782$ express an AR protein initiated from methionine 188 . These experiments do not allow us to deter- mine whether translation initiation at this position occurs at low levels in normal subjects or whether initiation at this methionine residue is due only to premature termination at the upstream termination codon.

Although COS cells transfected with R776 mutant cDNA synthesize the mutant $A R$ protein, the truncated receptor accumulates to a level that is at least 100 -fold less than in cells transfected with the cDNA encoding the normal AR. There are at least two possible mechanisms for reduced level of expression. First, although the sequences surrounding the ATG at amino acid 188 suggest that it can be used as an initiator methionine $(22,23)$, the process of translation from internal methionines may be inefficient (24). Second, the steady state level of AR mRNA may also be decreased, as has been demonstrated in other subjects with premature termination codons in the AR gene $(5,9)$. Alternatively, the AR protein itself may be unstable. It is clear that the effects leading to decreased AR expression are more pronounced in transfected COS cells than in fibroblast cultures (approximately fourfold decrease based on binding measurement).

To study the ligand binding kinetics of the mutant AR, $\mathrm{CHO}$ cells were stably transfected with the mutant expression plasmid (CMV776) carrying the Q60X mutation. CHO cells stably transfected with the CMV776 AR cDNA show normal levels of $\left[{ }^{3} \mathrm{H}\right]$ dihydrotestosterone binding, suggesting that in these transfected cells a larger amount of AR protein is ex- 
pressed than in genital skin fibroblasts. This phenomenon may be explained by the incorporation of multiple copies of the human AR gene expression plasmid into the genome of the transfected cells or by the fact that the transfected AR gene is driven by the powerful CMV promoter. Despite the differences in the level of expression, the $\mathrm{CHO}$ cells stably expressing the R776 mutant AR exhibit the same qualitative ligand binding abnormality (increased ligand dissociation) evident in the R776 and R782 genital skin fibroblast strains.

The AR, like several other members of the steroid receptor family, contains a transactivation domain in the $\mathrm{NH}_{2}$-terminal region. This domain was located between amino acid residues 141 and 338 by Simental et al. (25) and between amino acid 51 and 360 by Jentsen et al. (26). In their experiments, performed by inducing artificial deletions within the coding sequence of the human AR, removal of these two segments was followed by complete loss of transcriptional activity. The AR predicted for subjects R776 and R782 would lack 187 amino acids at the amino terminus of the receptor. The transactivation capacity of this receptor is markedly reduced when the assay is performed under standard circumstances ( $200 \mathrm{ng}$ of mutant AR expression plasmid cotransfected with $10 \mu \mathrm{g}$ of the MMTVCAT reporter plasmid). On the other hand, by transfecting increasing amounts of plasmid CMV-776, we were able to induce a substantial increase in the level of transactivation of the reporter gene, up to $30 \%$ of the normal control. These findings suggest that the first 187 amino acids are required for normal AR function. These results also imply that the regions deleted by Simental et al. (25) and Jentsen et al. (26) that resulted in a complete loss of receptor function may lie between amino acid residues 188 and 338 or 360 .

No previous mutation within the amino terminus of the AR has been reported to cause androgen resistance in humans, although in one patient with a qualitative abnormality of androgen binding, a truncation within the amino terminal glutamine homopolymeric segment accentuated the effect of an amino acid substitution in the hormone-binding domain of the receptor protein (11). Three groups have reported that androgen resistance in the $T \mathrm{fm}$ mouse is caused by a frame shift at amino acid position 371 followed by a premature termination of the AR protein occurring 42 amino acids later (27-29). Those studies suggested that reinitiation of AR protein synthesis at a methionine downstream of the premature stop codon might account for residual $\left[{ }^{3} \mathrm{H}\right]$ dihydrotestosterone binding found in the $T f m$ mouse. The current work documents that such a phenomenon can occur in cells and suggests that a combination of diminished receptor abundance and function cause the clinical phenotype.

As noted previously, studies of ligand binding in genital skin fibroblast cultures have defined categories of androgen resistance on the basis of qualitative and quantitative abnormalities of the AR protein (1). Studies in several laboratories have shown that the mechanisms responsible for receptor-binding negative androgen resistance encompass a broad spectrum of genetic abnormalities, including gene deletions, premature termination codons, amino acid substitutions, and alterations of the AR mRNA splicing. In contrast, the mechanisms causing receptor-binding positive androgen resistance are more homogeneous and result from single amino acid substitutions in the DNA-binding domain of the receptor protein.

The present paper describes the molecular characterization of two subjects with both qualitative and quantitative defects in androgen binding. Two mechanisms cause the androgen resistance in these subjects: reduction of the level of AR expression due to premature termination and inefficient initiation of translation at an internal methionine and diminished transactivation capacity of the truncated AR molecules that result. These findings have several implications. First, they demonstrate that alterations within the amino terminus of the human AR gene that do not change the structure of the DNA- and hormone-binding domains can cause complete androgen resistance. Second, these studies suggest that regions of the amino terminus of the AR demonstrated to be important for receptor function using in vitro assays $(25,26)$ are required for in vivo function. Third, it is evident from the current work that substantial alterations within the structure of amino terminus may result in only minor binding abnormalities. Studies of additional patients with complete or partial forms of androgen resistance and with subtle abnormalities of receptor binding will be necessary to determine what proportion is due to alterations within the amino terminus of the receptor.

\section{Acknowledgments}

We are indebted to Michelle Herbst and Diane Allman for technical support and to Brenda Hennis for secretarial and editorial assistance. Synthetic peptides were generously provided by Drs. M. Rosenblatt and J. Levy (Merck Sharp \& Dohme Research Laboratories, West Point, PA).

This work was supported by grant DK03892 from the National Institutes of Health, the Robert A. Welch Foundation (\#I-1090), and a grant from the Perot Family Foundation. M. Marcelli was supported by a grant awarded by the Endocrine Fellows Foundation.

\section{References}

1. Griffin, J. E., and J. D. Wilson. 1989. The androgen resistance syndromes: $5 \alpha$-reductase deficiency, testicular feminization, and related disorders. In The Metabolic Basis of Inherited Disease. C. R. Scriver, A. L. Beaudet, W. S. Sly, and D. Valle, editors. McGraw-Hill, New York. 1919-1944.

2. Brown, T. R., D. B. Lubahn, E. M. Wilson, D. R. Joseph, F. W. French, and C. J. Migeon. 1988. Deletion of the steroid-binding domain of the human androgen receptor gene in one family with complete androgen insensitivity syndrome: evidence for further genetic heterogeneity in this syndrome. Proc. Natl. Acad. Sci. USA. 85:8151-8155.

3. Quigley, C. A., K. J. Friedman, A. Johnson, R. G. Lafreniere, L. M. Silverman, D. B. Lubahn, T. R. Brown, E. M. Wilson, H. F. Willard, and F. S. French 1992. Complete deletion of the androgen receptor gene: definition of the null phenotype of the androgen insensitivity syndrome and determination of carrier status. J. Clin. Endocrinol. Metab. 74:927-933.

4. Marcelli, M., W. D. Tilley, C. M. Wilson, J. D. Wilson, J. E. Griffin, and M. J. McPhaul. 1990. A single nucleotide substitution introduces a premature termination codon into the androgen receptor gene of a patient with receptor-negative androgen resistance. J. Clin. Invest. 85:1522-1528.

5. Marcelli, M., W. D. Tilley, J. E. Griffin, J. D. Wilson, and M. J. McPhaul. 1990. Definition of the human androgen receptor gene structure permits the identification of mutations that cause androgen resistance: premature termination of the receptor protein at amino acid residue 588 causes complete androgen resistance. Mol. Endocrinol. 4:1105-1116.

6. Sai, T., S. Seino, C. Chang, M. Trifiro, L. Pinsky, A. Mhatre, M. Kaufman, B. Lambert, J. Trapman, A. O. Brinkmann, et al. 1990. An exonic point mutation of the androgen receptor gene in a patient with complete androgen insensitivity. Am. J. Hum. Genet. 46:1095-1100.

7. Trifiro, M., R. L. Prior, N. Sabbaghiam, L. Pinsky, M. Kaufman, E. G. Nylen, D. D. Belsham, C. R. Greenberg, and K. Wrogeman. 1991. Amber mutation creates a diagnostic MAcI site in the androgen receptor gene of a family with complete androgen insensitivity. Am. J. Hum. Genet. 40:493-499.

8. Brown, T. R., D. B. Lubahn, E. M. Wilson, F. W. French, C. J. Migeon, and J. L. Corden. 1990. Functional characterization of naturally occurring mutant androgen receptors from subjects with complete androgen insensitivity. Mol. Endocrinol. 4:1759-1772.

9. Marcelli, M., W. D. Tilley, S. Zoppi, J. E. Griffin, J. D. Wilson, and M. J. McPhaul. 1991. Androgen resistance associated with a mutation of the androgen receptor at amino acid 772 ( $\mathrm{Arg} \rightarrow \mathrm{Cys}$ ) results from a combination of decreased 
messenger ribonucleic acid levels and impairment of receptor function. J. Clin Endocrinol. Metab. 73:318-325.

10. Lubahn, D. B., T. R. Brown, J. A. Simental, H. N. Higgs, C. J. Migeon, E. M. Wilson, and F. S. French. 1989. Sequence of the intron/exon junctions of the coding region of the human androgen receptor gene and identification of a point mutation in a family with complete androgen insensitivity. Proc. Natl. Acad. Sci. USA. 86:9534-9538.

11. McPhaul, M. J., M. Marcelli, W. D. Tilley, J. E. Griffin, R. F. Isidro-Gutierrez, and J. D. Wilson. 1991. Molecular basis of androgen resistance in a family with qualitative abnormality of the androgen receptor and responsive to highdose androgen therapy. J. Clin. Invest. 87:1413-1421.

12. Marcelli, M., S. Zoppi, P. B. Grino, J. E. Griffin, J. D. Wilson, and M. J. McPhaul. 1991. A mutation in the DNA-binding domain of the androgen receptor gene causes complete testicular feminization in a patient with receptor-positive androgen resistance. J. Clin. Invest. 87:1123-1126.

13. Zoppi, S., M. Marcelli, J.-P. Deslypere, J. E. Griffin, J. D. Wilson, and M. J. McPhaul. 1992. Amino acid substitutions in the DNA-binding domain of the human androgen receptor are a frequent cause of receptor-binding positive androgen resistance. Mol. Endocrinol. 6:409-415.

14. Wilson, C. M., J. E. Griffin, J. D. Wilson, M. Marcelli, S. Zoppi, and M. J. McPhaul. 1992. Immunoreactive androgen receptor expression in subjects with androgen resistance. J. Clin. Endocrinol. Metab. 75:1474-1478.

15. Husmann, D. A., C. M. Wilson, M. J. McPhaul, W. D. Tilley, and J. D. Wilson. 1990. Antipeptide antibodies to two distinct regions of the androgen receptor localize the receptor protein to the nuclei of target cells in the rat and human prostate. Endocrinology. 126:2359-2368.

16. Frost, E., and J. Williams. 1978. Mapping temperature sensitive and hostrange mutations of adenovirus type 5 by marker rescue. Virology. 91:39-50.

17. Southern, P. J., and P. Berg. 1982. Transformation of mammalian cells to antibiotic resistance with a bacterial gene under control of the SV40 early region promoter. J. Mol. Appl. Genet. 1:327-341.

18. Griffin, J. E., and J. D. Wilson. 1977. Studies on the pathogenesis of the incomplete forms of androgen resistance in man. J. Clin. Endocrinol. Metab. 45:1137-1143.
19. Grino, P. B., R. F. Isidro-Gutierrez, J. E. Griffin, and J. D. Wilson. 1989. Androgen resistance associated with a qualitative abnormality of the androgen receptor and responsive to high dose androgen therapy. J. Clin. Endocrinol. Me tab. 68:578-584.

20. Gorman, C. M., L. F. Moffat, and B. H. Havard. 1982. Recombinant genomes which express chloramphenicol acetyl transferase in mammalian cells Mol. Cell. Biol. 2:1044-1051.

21. Hall, C., P. Jacob, G. Ringold, and F. Lee. 1983. Expression and regulation of Escherichia coli LacZ gene fusions in mammalian cells. J. Mol. Appl. Genet. 2:101-109.

22. Kozak, M. 1984. Selection of initiation sites by eucaryotic ribosomes: effect of inserting AUG triplets upstream from the coding sequence for preproinsulin. Nucleic Acids Res. 12:3873-3893.

23. Kozak, M. 1987. Effects of intercistronic length on the efficiency of reinitiation by eucaryotic ribosomes. Mol. Cell. Biol. 7:3438-3445.

24. Peabody, D., and P. Berg. 1986. Termination reinitiation occurs in translation of mammalian cell mRNA. Mol. Cell. Biol. 6:2695-2703.

25. Simental, J. A., M. Sar, M. V. Lane, F. S. French, and E. M. Wilson. 1991. Transcriptional activation and nuclear targeting signals of the human androgen receptor. J. Biol. Chem. 266:510-518.

26. Jentsen, G., H. A. G. M. van der Korput, C. van Vroonhoven, T. vander Kwast, J. Trapman, and A. O. Brinkmann. 1991. Domains of the human androgen receptor involved in steroid binding transcriptional activation and subcellular localization. Mol. Endocrinol. 5:1396-1404.

27. He, W. W., M. V. Kumar, and D. J. Tindall. 1991. A frame-shift mutation in the androgen receptor gene causes complete androgen insensitivity in the testicular-feminized mouse. Nucleic Acids Res. 19:2373-2378.

28. Charest, N. J., Z.-X. Zhou, D. B. Lubahn, K. L. Olsen, E. M. Wilson, and F. S. French. 1991. A frame shift mutation destabilizes androgen receptor messenger RNA in the Tfm mouse. Mol. Endocrinol. 5:573-581.

29. Gaspar, M.-L., T. Meo, P. Bourgarel, J.-L. Guenet, and M. Tosi. 1991. A single base deletion in the $T f m$ androgen receptor gene creates a short-lived messenger RNA that directs internal translation initiation. Proc. Natl. Acad. Sci. USA. 88:8606-8610. 